\title{
Negligible risk of hepatocellular carcinoma in chronic hepatitis B patients in immune-tolerant phase: Myth or fact
}

\author{
Terry Cheuk-Fung Yip ${ }^{1,2,3}$, Grace Lai-Hung Wong ${ }^{1,2,3}$, and Vincent Wai-Sun Wong ${ }^{1,2,3}$ \\ ${ }^{1}$ Medical Data Analytics Centre, ${ }^{2}$ Department of Medicine and Therapeutics, ${ }^{3}$ Institute of Digestive Disease, The Chinese University of \\ Hong Kong, Hong Kong SAR, China
}

Keywords: Hepatitis B; Immune tolerance; Fibrosis-4 index; Liver fibrosis

\section{See Article on Page 295}

In chronic hepatitis B virus (HBV) infection, the term immunetolerant phase has been used for decades to describe the early years of infection in patients who are infected perinatally. ${ }^{1}$ Yet it has been challenged that there is no genuine immune tolerance, as immunological studies revealed that children and young adults with chronic hepatitis B (CHB) have an immune profile that is not as compromised as in older patients. ${ }^{2}$ The practice guidelines by the European Association for the Study of the Liver (EASL) in 2017 even abandoned the term "immune-tolerant phase". Instead, a new nomenclature - phase 1 or hepatitis B e antigen (HBeAg)positive chronic infection - was used. ${ }^{3}$ This new name remains to be widely adopted, as the latest 2018 American guidance $^{4}$ and the 2015 Asian Pacific practice guidelines ${ }^{5}$ continue to use the old term. The practice guidance by the American Association for the Study of Liver Diseases (AASLD) defined immune-tolerant phase as positive HBeAg, very high serum HBV DNA level (typically above 1,000,000 IU/mL), normal or minimally elevated transaminases, and liver biopsy or non-invasive test results showing no fibrosis and minimal inflammation. ${ }^{4}$ Unlike EASL that defined normal alanine aminotransferase (ALT) as $<40 \mathrm{IU} / \mathrm{L}$ for both gender, AASLD defined normal ALT as $<35$ and $<25$ IU/L for males and females. ${ }^{3,4}$ The Asian Pacific practice guidelines defined this phase with positive HBeAg, a normal ALT ( $<40 \mathrm{IU} / \mathrm{L}$ ) and a lower threshold of serum HBV DNA $(>20,000 \mathrm{lU} / \mathrm{mL})$ and put up age as one of the criteria (typically below 30 years old). ${ }^{5}$ The Korean Association for the study of the Liver defined immune-tolerant phase as positive $H B e A g$, very high serum HBV DNA levels of $\geq 10^{7} \mathrm{IU} / \mathrm{mL}$, persistently normal ALT ( $\leq 34 \mathrm{IU} / \mathrm{L}$ in males and $\leq 30 \mathrm{IU} / \mathrm{L}$ in females), and no or minimal liver necroinflammation. ${ }^{6}$

It is often challenging to differentiate immune-tolerant phase from immune-active phase, or named as phase 2/HBeAg-positive chronic hepatitis, because the key distinguishing features of elevated serum ALT may be easily missed if the follow-up interval is not frequent enough. ${ }^{7}$ This affects our treatment plan, as by far the international guidelines do not support treating patients in

\section{Abbreviations:}

AASLD, American Association for the Study of Liver Diseases; ALT, alanine aminotransferase; $C H B$, chronic hepatitis B; EASL, European Association for the Study of the Liver; FIB-4, fibrosis-4; HBeAg, hepatitis B e antigen; HBV, hepatitis B virus; HCC, hepatocellular carcinoma

\author{
Corresponding author: Vincent Wai-Sun Wong \\ Department of Medicine and Therapeutics, Prince of Wales Hospital, 9/F, \\ 30-32 Ngan Shing Street, Shatin, Hong Kong SAR, China \\ Tel: +852-3505-1205, Fax: +852-2637-3852 \\ E-mail:wongv@cuhk.edu.hk \\ https://orcid.org/0000-0003-2215-9410
}




\section{CLINCAL and MOLECULAR}

immune-tolerant phase while persistently immune-active patients deserve antiviral treatment. ${ }^{3-5}$ The AASLD explicitly recommends against antiviral therapy for adults with immune-tolerant CHB. ${ }^{4}$ Furthermore, this dubious classification also poses challenges to study the risk of hepatocellular carcinoma (HCC) of immune-tolerant phase, as some patients may have phase transition between clinical assessments. ${ }^{8}$ This also explains while most of the studies reported a minimal risk of HCC in immune-tolerant patients, one particular study from Korea showed a conflicting result that untreated immune-tolerant patients had higher HCC risk than treat- ed HBeAg-positive immune-active patients. ${ }^{9}$

In this issue of Clinical and Molecular Hepatology, Jeon et al. ${ }^{10}$ report the $\mathrm{HCC}$ risk in 125 immune-tolerant patients and compare that with 2,024 HBeAg-positive non-cirrhotic patients who received antiviral treatment. They defined immune-tolerant patients as untreated patients who had positive $\mathrm{HBeAg}$, HBV DNA level $>20,000 \mathrm{IU} / \mathrm{mL}$, and normal ALT level of $<40 \mathrm{U} / \mathrm{L}$. They further defined a low risk group of immune-tolerant patients using the fibrosis-4 (FIB-4) index $<1.45$, which reflected a minimal fibrotic burden. At a median follow-up of 7 years, none of the immune-

Table 1. Comparison of three studies on risk of hepatocellular carcinoma among patients with immune-tolerant chronic hepatitis B

\begin{tabular}{|c|c|c|c|}
\hline Data source & $\begin{array}{c}\text { Jeon et al. } .^{10} \\
\text { (Single-center/South Korea) }\end{array}$ & $\begin{array}{c}\text { Kim et al. }{ }^{9} \\
\text { (Single-center/South Korea) }\end{array}$ & $\begin{array}{c}\text { Lee et al. } .^{8} \\
\text { (Multicenter/South Korea: } 2 \text {, } \\
\text { Hong Kong: } 1 \text { ) }\end{array}$ \\
\hline \multicolumn{4}{|l|}{$\begin{array}{l}\text { Definition related to } \\
\text { immune-tolerant phase }\end{array}$} \\
\hline Hepatitis B e antigen status & Positive & Positive & Positive \\
\hline HBV DNA level & $>20,000 \mathrm{IU} / \mathrm{mL}$ & $>20,000 \mathrm{IU} / \mathrm{mL}$ & $>1,000,000 \mathrm{IU} / \mathrm{mL}$ \\
\hline ALT level & Normal (<40 U/L) & $\begin{array}{l}\text { Normal (<19 U/L for females and } \\
<30 \mathrm{U} / \mathrm{L} \text { for males) }\end{array}$ & Normal $(<40 \mathrm{U} / \mathrm{L})$ \\
\hline Age & No restriction & No restriction & $<40$ years \\
\hline Antiviral treatment & Untreated & Untreated & Untreated \\
\hline Cirrhosis status & $\begin{array}{l}\text { Non-cirrhotic; subgroups with } \\
\text { low/high FIB-4 were studied }\end{array}$ & Non-cirrhotic & Non-cirrhotic \\
\hline $\begin{array}{l}\text { Method to handle phase } \\
\text { change in immune-tolerant } \\
\text { patients }\end{array}$ & $\begin{array}{l}\text { Patients who had phase change } \\
\text { were censored at phase change } \\
\text { in per-protocol analysis, or not } \\
\text { censored in intention-to-treat } \\
\text { analysis }\end{array}$ & $\begin{array}{l}\text { Patients who had phase change } \\
\text { within } 1 \text { year were excluded. } \\
\text { Patients were not censored at } \\
\text { phase change }\end{array}$ & $\begin{array}{l}\text { Patients who had phase change } \\
\text { were censored at phase change }\end{array}$ \\
\hline \multicolumn{4}{|l|}{ Study population } \\
\hline Clinical characteristics & Immune-tolerant patients $(n=125)$ & Immune-tolerant patients $(n=413)$ & Immune-tolerant patients $(n=194)$ \\
\hline Age (years) & $39(28-51)$ & $38 \pm 11$ & $32 \pm 6$ \\
\hline Male sex & 77 (61.6) & $276(66.8)$ & $84(43.3)$ \\
\hline HBV DNA (log IU/mL) & $8.0(7.8-8.0)$ & $8.0(7.0-8.4)$ & $8.1 \pm 0.6$ \\
\hline $\operatorname{ALT}(U / L)$ & $23(19-31)$ & $19(16-25)$ & $25(19-32)$ \\
\hline Albumin (g/dL) & $4.4(4.1-4.6)$ & $4.0(3.8-4.3)$ & $4.4 \pm 0.4$ \\
\hline Total bilirubin (mg/dL) & $0.7(0.5-0.9)$ & $0.9(0.7-1.1)$ & $0.8 \pm 0.5$ \\
\hline Platelet $\left(\times 10^{9} / \mathrm{L}\right)$ & $210(179-262)$ & $204(167-242)$ & $232 \pm 63$ \\
\hline Follow-up duration (years) & $7.2(4.7-9.2)$ & $4.9(2.4-8.6)$ & $5.7(2.1-9.8)$ \\
\hline \multicolumn{4}{|l|}{ Clinical outcomes } \\
\hline Hepatocellular carcinoma & $\begin{array}{c}2(1.6) \\
0(0) \text { among FIB-4 }<1.45\end{array}$ & $\begin{array}{c}24(5.8) \\
-\end{array}$ & $0(0)$ \\
\hline
\end{tabular}

Values are presented as mean \pm standard deviation, median (interquartile range), or number (\%).

HBV, hepatitis B virus; FIB-4, fibrosis-4; ALT, alanine aminotransferase. 
Terry Cheuk-Fung Yip, et al.

$\mathrm{HCC}$ risk in immune-tolerant phase

tolerant patients with FIB-4 $<1.45$ developed HCC, as compared to a cumulative $\mathrm{HCC}$ incidence of $1.4 \%$ at 5 years among treated patients with FIB-4 $<1.45$, though the difference between the two groups did not reach statistical significance. In contrast, 2/34 (5.9\%) immune-tolerant patients with FIB-4 $\geq 1.45$ developed HCC, with a 5-year cumulative HCC incidence of $6.0 \%$, which was significantly higher than that in immune-tolerant patients with FIB-4 $<1.45$. The analysis remained robust with and without censoring of immune-tolerant patients at the time of transition to immune-active phase.

The findings of Jeon et al. $^{10}$ are in line with a multicenter study from Lee et al. ${ }^{8}$ that showed no immune-tolerant patients developed HCC during a median follow-up of 5.7 years. It is however different from that of another Korean study from Kim et al., ${ }^{9}$ which suggested that untreated immune-tolerant CHB patients have a higher risk of HCC than treated HBeAg-positive immuneactive patients. In Kim et al.'s study, ${ }^{9} 24 / 413$ (5.8\%) of immunetolerant patients developed HCC at a median follow-up of 5 years, with a 5-year cumulative incidence of 4.2\%. In contrast, 54/1,497 (3.6\%) HBeAg-positive immune-active patients developed HCC, i.e., a 5-year cumulative incidence of $1.6 \%$. Numerically, the HCC incidence of immune-tolerant patients in Kim et al.'s study ${ }^{9}$ is higher than that in Jeon et al.' $\mathrm{s}^{10}$ and Lee et al.' $\mathrm{s}^{8}$ studies. Table 1 compares the definition, study population, and the methods used to handle phase change of immune-tolerant patients in the three studies. Basically, the definition of immune-tolerant CHB was similar between Jeon et al. ${ }^{10}$ and Kim et al. ${ }^{9}$ The baseline HBV DNA level, ALT level, and age were quite comparable between their immune-tolerant patients. A more stringently defined immunetolerant phase with HBV DNA level above 1,000,000 IU/mL and age $<40$ years was adopted by Lee et al. ${ }^{8}$ the patients were therefore younger and had generally high HBV DNA.

However, the method of handling phase change may partly explain the difference in HCC cumulative incidence. While Jeon et al. ${ }^{10}$ and Lee et al. ${ }^{8}$ handled that by censoring patients after phase change, Kim et al. ${ }^{9}$ continued to follow the patients after they transited from immune-tolerant to immune-active CHB. Lee et al. ${ }^{8}$ showed that the 5 -year cumulative incidence of change from immune-tolerant to immune-active phase can reach about $40 \%$. Given that those patients did not receive antiviral treatment under their definition of immune-tolerant patients, those patients are at risk of disease progression as well as HCC development. Based on the result of Kim et al.'s study, ${ }^{9}$ one may suggest earlier antiviral treatment in selected immune-tolerant patients, yet those selected may indeed be immune-active patients who already fulfil treat- ment criteria, and the remaining immune-tolerant patients are generally safe from disease progression and do not deserve antiviral treatment. In fact, none of the patients in Lee et al.'s study, ${ }^{8}$ and among patients with FIB-4 $<1.45$ in Jeon et al.'s study ${ }^{10}$ developed HCC. Even so, Kim et al.'s study ${ }^{9}$ can partly reflect the clinical consequence of absence of antiviral treatment during immune-tolerant phase. Some of the patients might have hidden hepatic necroinflammation during immune-tolerant phase, which may partly contribute to the subsequent HCC development in immune-active phase. As echoed by Jeon et al.'s study, ${ }^{10}$ some immune-tolerant patients can indeed have a FIB-4 $>1.45$, which is associated with an increased HCC risk. A detailed description of patients who developed HCC will help to distinguish whether the patients were still in immune-tolerant phase at the time of HCC development, and to understand more on the fibrotic burden and degree of hepatic necroinflammation in this hidden but potentially high-risk group of CHB patients.

What are the implications of the study by Jeon et al.? ${ }^{10}$ Above all, it is reassuring to see that patients who are truly in the immune-tolerant phase have very low risk of HCC development. The keyword here, however, is "truly". Clinicians need to monitor patients longitudinally to ensure that the ALT level remains normal. In patients with CHB, high-normal or mildly elevated ALT is associated with increased HCC risk." Current guidelines provide conflicting definitions for normal ALT in patients with CHB (40 U/L by EASL and Asian Pacific; $35 \mathrm{U} / \mathrm{L}$ in men and $25 \mathrm{U} / \mathrm{L}$ in women by AASLD). As data accumulate, a unified definition would be useful to practicing clinicians.

It is also important to perform non-invasive tests of fibrosis to ensure that we are not missing patients in the immune-active phase with fibrosis progression. The study by Jeon and colleagues suggests that a fibrosis score as simple as the FIB-4 index can be used to identify a low-risk population. Although FIB-4 only has modest accuracy for advanced fibrosis, it has a high negative predictive value and is well suited for initial screening. In the general population, people with persistently low FIB-4 are at extremely low risk of cirrhosis, HCC and hepatic decompensation. ${ }^{12}$ In specialist settings, specific fibrosis biomarkers and liver stiffness measurement by ultrasound elastography or magnetic resonance elastography would provide a more accurate estimation of the degree of liver fibrosis. ${ }^{13}$

As HBV cure has become a hot area of research, we may one day have drugs that can achieve a high rate of functional cure, i.e., $\mathrm{HBsAg}$ seroclearance, regardless of the phase of the disease. Before that happens, one should be cautious in initiating treatment 
for patients in immune-tolerant phase. A Korean retrospective multicenter study showed that in patients with positive HBeAg, HBV DNA >20,000 IU/mL, and normal ALT, the median time to complete viral suppression was 17 months in patients who started antiviral treatment during immune-tolerant phase, as compared to 71 months in patients without treatment. ${ }^{14} \mathrm{As}$ a counter-example, in a randomized trial of patients with positive HBeAg, high baseline serum HBV DNA $>1.7 \times 10^{7} \mathrm{IU} / \mathrm{mL}$ and normal ALT, treatment with tenofovir disoproxil fumarate for 4 years could only achieve HBeAg seroconversion in $4.8 \%$ and HBV DNA suppression to $<29$ $\mathrm{IU} / \mathrm{mL}$ in $45 \% .{ }^{15}$ Apparently, without the help of host immune clearance, current antiviral treatment might not be potent enough to completely suppress the virus in patients with very high pretreatment serum HBV DNA. Partial viral suppression may also hinder transition into the immune-active phase and delay HBeAg seroconversion. How such suboptimal response would affect the patients' lifetime risk of HCC and disease progression is currently unknown. ${ }^{16}$ Fortunately, based on data from Jeon et al.' paper, ${ }^{10}$ one may safely withhold treatment and monitor patients with immune-tolerant CHB, so far if the ALT level and non-invasive tests of fibrosis remain normal.

\section{Authors' contributions}

All authors were responsible for the interpretation of data, the drafting, and critical revision of the manuscript for important intellectual content.

\section{Conflicts of Interest}

Terry Yip has served as an advisory committee member and a speaker for Gilead Sciences.

Grace Wong has served as an advisory committee member for Gilead. She has also served as a speaker for Abbott, Abbvie, Bristol-Myers Squibb, Echosens, Furui, Gilead, Janssen, and Roche.

Vincent Wong served as a consultant or advisory board member for 3V-BIO, AbbVie, Allergan, Boehringer Ingelheim, Center for Outcomes Research in Liver Diseases, Echosens, Gilead Sciences, Hanmi Pharmaceutical, Intercept, Inventiva, Merck, Novartis, Novo Nordisk, Perspectum Diagnostics, Pfizer, ProSciento, Sagimet Biosciences, TARGET PharmaSolutions, and Terns; and a speaker for AbbVie, Bristol-Myers Squibb, Echosens, and Gilead Sciences. He has received a grant from Gilead Sciences to support fatty liver research.

\section{REFERENCES}

1. Wong GL. Management of chronic hepatitis B patients in immunetolerant phase: what latest guidelines recommend. Clin Mol Hepatol 2018;24:108-113.

2. Bertoletti A, Ferrari C. Adaptive immunity in HBV infection. J Hepatol 2016;64(1 Suppl):S71-S83.

3. European Association for the Study of the Liver. EASL 2017 clinical practice guidelines on the management of hepatitis $B$ virus infection. J Hepatol 2017;67:370-398.

4. Terrault NA, Lok ASF, McMahon BJ, Chang KM, Hwang JP, Jonas $M M$, et al. Update on prevention, diagnosis, and treatment of chronic hepatitis B: AASLD 2018 hepatitis B guidance. Hepatology 2018:67:1560-1599.

5. Sarin SK, Kumar M, Lau GK, Abbas Z, Chan HL, Chen CJ, et al. Asian-Pacific clinical practice guidelines on the management of hepatitis B: a 2015 update. Hepatol Int 2016;10:1-98.

6. Korean Association for the Study of the Liver (KASL). KASL clinical practice guidelines for management of chronic hepatitis B. Clin Mol Hepatol 2019;25:93-159.

7. Liang LY, Wong GL. Unmet need in chronic hepatitis B management. Clin Mol Hepatol 2019;25:172-180.

8. Lee HW, Chon YE, Kim BK, Yip TC, Tse YK, Wong GL, et al. Negligible HCC risk during stringently defined untreated immune-tolerant phase of chronic hepatitis B. Eur J Intern Med 2021;84:68-73.

9. Kim GA, Lim YS, Han S, Choi J, Shim JH, Kim KM, et al. High risk of hepatocellular carcinoma and death in patients with immunetolerant-phase chronic hepatitis B. Gut 2018;67:945-952.

10. Jeon MY, Kim BK, Lee JS, Lee HW, Park JY, Kim DY, et al. Negligible risks of hepatocellular carcinoma during biomarker-defined immunetolerant phase for patients with chronic hepatitis B. Clin Mol Hepatol 2021;27:295-304.

11. Wong GL, Chan HL, Tse YK, Yip TC, Lam KL, Lui GC, et al. Normal on-treatment ALT during antiviral treatment is associated with a lower risk of hepatic events in patients with chronic hepatitis B. J Hepatol 2018;69:793-802.

12. Hagström H, Talbäck M, Andreasson A, Walldius G, Hammar N. Repeated FIB-4 measurements can help identify individuals at risk of severe liver disease. J Hepatol 2020;73:1023-1029.

13. Liang LY, Wong VW, Tse YK, Yip TC, Lui GC, Chan HL, et al. Improvement in enhanced liver fibrosis score and liver stiffness measurement reflects lower risk of hepatocellular carcinoma. Aliment Pharmacol Ther 2019;49:1509-1517.

14. Chang Y, Choe WH, Sinn DH, Lee JH, Ahn SH, Lee H, et al. Nucleos(t) ide analogue treatment for patients with hepatitis $B$ virus (HBV) e antigen-positive chronic HBV genotype C infection: a nationwide, multicenter, retrospective study. J Infect Dis 2017;216:1407-1414.

15. Chan HL, Chan CK, Hui AJ, Chan S, Poordad F, Chang TT, et al. 
Terry Cheuk-Fung Yip, et al. $\mathrm{HCC}$ risk in immune-tolerant phase

Effects of tenofovir disoproxil fumarate in hepatitis B e antigenpositive patients with normal levels of alanine aminotransferase and high levels of hepatitis B virus DNA. Gastroenterology 2014;146:1240-1248.
16. Wong GL, Chan HL, Chan HY, Tse PC, Tse YK, Mak CW, et al. Accuracy of risk scores for patients with chronic hepatitis $B$ receiving entecavir treatment. Gastroenterology 2013;144:933-944. 